\title{
Is the rationale behind the new dose limits of ICRP still valid ?*
}

\author{
S. PRETRE*, E. STOLL**
}

(Manuscrit reçu le 23 novembre 1994,

révisé le 10 février 1995, accepté le 4 avril 1995)

ABSTRACT Radiological protection is based on the assumption that even small doses of ionizing radiation are detrimental. In 1990 the International commission on radiological protection (ICRP) published its latest estimates concerning radiation risk and how to regulate it. To deduce its risk factors, ICRP relied on the epidemiological data from Hiroshima and Nagasaki, but took into account that low dose-rates are, per unit dose, less detrimental than high dose rates as suffered by the people exposed in these bombed cities. This was achieved by introducing a controversial correction factor called "Dose and dose rate effectiveness factor" (DDREF). During the last 5 years radiation research has revealed some new aspects, which slightly modify the situation but globally do not invalidate the scientific basis of the 1990 ICRP recommendations. The authors therefore express the view that the basic dose limit for radiation workers, which is $20 \mathrm{mSv}$ per year, will remain valid for the foreseeable future. Some doubts are however expressed concerning the rationale leading to the dose limit for the public, which seems to be unnecessarily low.

RÉSUMÉ La protection radiologique est basée sur l'hypothèse linéaire attribuant aussi aux faibles doses la capacité potentielle d'induire un détriment sanitaire. La Commission internationale de protection radiologique (CIPR) a publié en 1990 ses dernières estimations du risque radiologique et les recommandations correspondantes. Pour en déduire son coefficient de risque, la CIPR se base surtout sur les observations épidémiologiques des survivants d'Hiroshima et de Nagasaki. En outre, la CIPR a dû prendre en considération le fait que les faibles débits de dose sont, par unité de dose, moins préjudiciables que les hauts débits de dose tels que ceux d'Hiroshima et de Nagasaki. Cette différenciation conduisit à l'introduction du facteur correctif FEDDD (facteur d'efficacité de la dose et du débit de dose) très controversé. La recherche en radiobiologie pendant les 5 dernières années a mis en évidence quelques aspects nouveaux qui modifient légèrement la situation mais qui, globalement, n'invalident pas la base scientifique des recommandations "CIPR 60". Les auteurs estiment donc que la limite principale de dose pour les travailleurs $(20 \mathrm{mSv} / \mathrm{an})$ repose sur des bases robustes, et va rester en vigueur pendant de nombreuses années. D'autre part, les auteurs expriment quelques doutes sur une étape du raisonnement conduisant à la limite de dose pour le public qu'ils estiment inutilement basse.

\footnotetext{
* Communication présentée lors de la journée "Radioprotection" organisée dans le cadre de la conférence ENC'94 "Occupational radiation protection in NPPs", Lyon, 4 octobre 1994. ** Swiss federal nuclear safety inspectorate, CH-5232 Villigen-HSK, Suisse.
} 


\section{Introduction}

Very high doses of ionising radiation are definitely detrimental and the corresponding effects on human beings are well known. With respect to small doses, the situation is not so clear. Our information stems largely from observation of the survivors in Hiroshima and Nagasaki. These investigations showed :

- a statistically significant increase in cancer mortality at dose levels above $0.2 \mathrm{~Sv}[10]$;

- convincing hints in favour of a non-threshold linear dose-effect relationship at smaller dose levels [10];

- an increased cancer sensitivity of small children as compared to adults $[10]$;

- a statistically not significant indication of increased hereditary disorders in the descendants of the exposed population [11], suggesting that the doubling dose could be situated between 1.7 and $2.2 \mathrm{~Sv}$;

- an increased occurrence of malformations, especially small head size, and mental retardation among children exposed in utero [11].

These findings agree with other studies of radiation exposed persons, especially radiotherapeutic patients, as well as animal experiments which clearly show that moderately high doses of ionising radiation increase the occurrence of leukaemias and solid tumours, are a cause of hereditary disorders and may damage the mammalian embryo and fetus. The harm due to radiation-induced cancer is predominant and constitutes the limiting factor. Radiation induced hereditary damage is barely detectable even among the survivors of Hiroshima and Nagasaki, and damage after exposure in utero needs higher doses than those that are encountered by females occupationally exposed to radiation.

In terms of radiation protection this means that we primarily have to protect workers against the oncogenic effect of ionising radiation. And the most sensitive group of workers are pregnant females, because of the possibility to induce a cancer in childhood due to fetal exposure. The assumption is that the fetus is at least as sensitive as small children.

\section{The radiation risk}

The already mentioned investigations in Hiroshima and Nagasaki are the most important basis for the estimation of radiation risk. Two steps are necessary to quantify this risk :

- the excess cancer mortality of the survivors has to be determined,

- the individual dose of the survivors has to be calculated.

A careful epidemiological study was started in 1950 and is still going on, to follow the health of the exposed population group and to register the causes of death. 
The reconstruction of the individual doses is a major enterprise that is also still going on. A first approach in the mid sixties turned out to be rather inaccurate. The whole task was redone in the eighties and there are still open questions primarily concerning the neutron doses in the low dose zone of Hiroshima. However, we are today quite confident that the achieved dose determinations are accurate, since there are several possibilities of checking the results. A very new test relies on the determination of reciprocal chromosome translocations in the blood cells of survivors. These translocations are very stable and are therefore, even today, a good indication of the dose received in 1945. The results of such a test show that the dose determination of most of the persons examinated turned out to be accurate within $\pm 33 \%$, which is quite $\operatorname{good}[5]$.

Today we are waiting for the cancer mortality data until 1990. Roughly 5 years ago, when the results till 1985 became available, these data were evaluated by different groups of experts. The expert group of the United Nations (UNSCEAR, United Nations scientific committee on the effects of atomic radiation) concluded that the most likely increase in cancer mortality due to ionising radiation was $7-11 \%$ per sievert [12]. A different expert group of the U.S. National research council arrived at $8 \%$ per sievert [8]. These results were examined by the International commission on radiological protection (ICRP) which concluded that a $10 \%$ increase of cancer mortality per sievert, for the exposed population of Hiroshima and Nagasaki, is the best estimate [2].

Epidemiological studies of radiation exposed patients are also available. The cancer risk derived from these studies is generally somewhat lower than the mentioned risk factors from the Hiroshima and Nagasaki study. But the difference is not dramatic and the results from Japan are considered to be more reliable because medical exposure is normally a partial body exposure making dosimetry and interpretation more complicated.

It would however be unreasonable to use without adaptation this same risk factor for radiation workers. There is convincing evidence that a radiation dose accumulated in small fractions or with low dose rate is less dangerous than the same dose absorbed as an acute exposure of short duration. To allow for this difference ICRP decided to introduce a "dose and dose rate effectiveness factor" (DDREF) of 2. That means ICRP reduced the risk factor for radiation protection purposes to $5 \%$ per sievert for the population and to $4 \%$ per sv for a working force, since small children, which have the highest radiation risk, are excluded from the latter.

\section{How reliable are these values?}

It is fair to say that several assumptions which have been used to derive these risk factors are not much more than an educated guess. These are :

- the assumption that a linear relationship between dose and risk exists even in the very low dose region; that means that all doses are considered to be detrimental; 
- the DDREF of 2 which can be justified from the A-bomb survivors data, but higher values are nevertheless possible [11] ; this problem will be discussed later on ;

- the assumption that radiation increases the risk of spontaneous solid tumours in a multiplicative way (the radiation risk is not additive to the spontaneous cancer risk; it is rather obtained by multiplying the age dependent spontaneous risk by a constant factor.)

It is therefore fair to admit that the radiation risk factor for low dose and dose rate irradiation relies, to a great extent, on reasonable and prudent assumptions and not only on proven facts.

Nevertheless our knowledge increases and the uncertainty gradually decreases: The choice of the risk model is illustrating this. When the epidemiological study in Hiroshima and Nagasaki was started in 1950, it was already obvious that, as a result of the irradiation, the leukaemia incidence among the survivors was high. Gradually, the leukaemia incidence returned to a normal value as shown in figure 1a [4]. At that time the incidence of solid tumours began to increase and everybody expected that this increase would also.gradually disappear. But unlike the increase in leukaemia risk, which looks like an additive risk increment, the risk of solid tumours rather increased by a constant factor (multiplicative risk) as shown in figure 1b [4]. This difference is important since the solid tumours outnumber the leukaemias by roughly a factor of

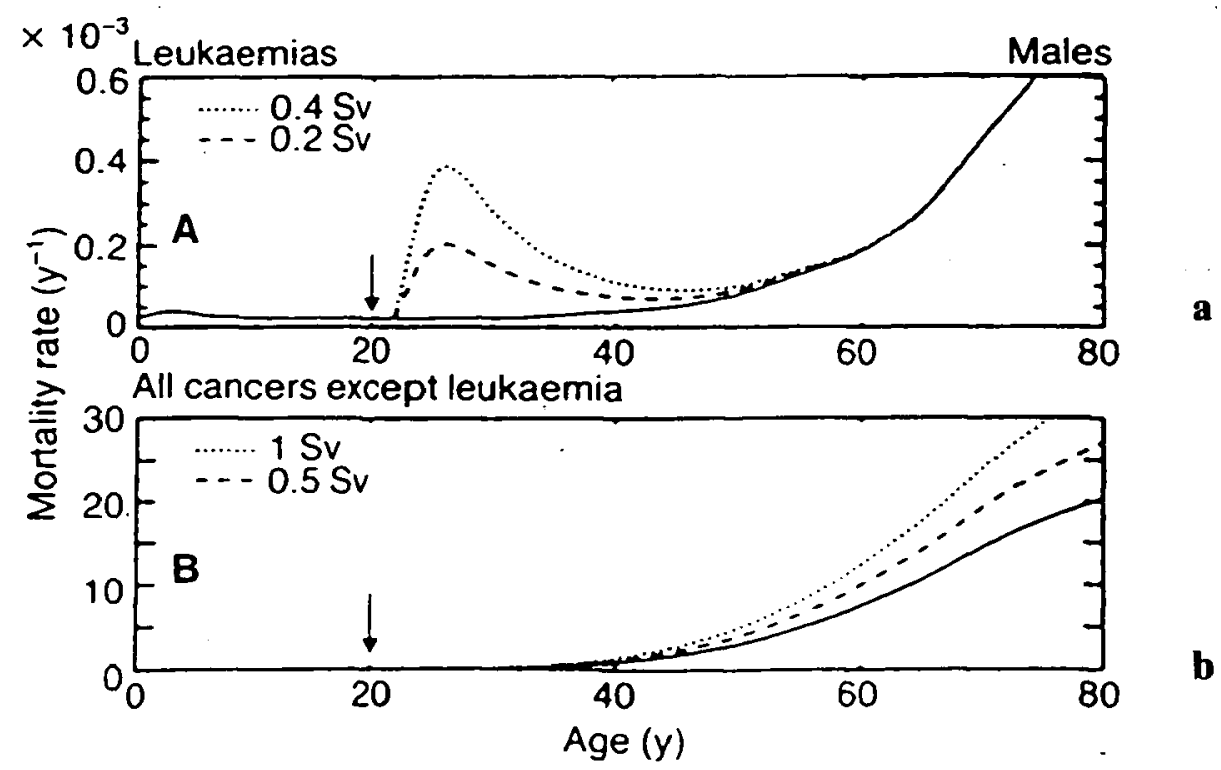

Fig. 1 - Age specific spontaneous mortality rates from leukaemia and other cancers (solid lines) and the increased rates due to an acute irradiation at age 20. These theoretical curves were obtained from the ICRP-60 model without DDREF factor, from [4, p. 273].

Taux de mortalité spontanée par leucémie et par d'autres cancers en fonction de l'âge (trait plein) et accroissement de ces taux par une irradiation aiguë à 20 ans. Les courbes théoriques sont dérivées du modèle de la CIPR 60 sans le facteur FEDDD, d'après [4, p. 273]. 
10. It must be kept in mind that it is still possible that the increased risk for solid tumours also begins to regress. Cancer incidence data tend to indicate such a decrease [10]. However, such a development would hardly affect the radiation risk of workers since those people who were 18 years old and older in 1945 have now to a great extent outlived their lifetime and their risk is known. But the risk of these persons irradiated at young ages is, for that reason, still rather inaccurately known.

\section{The dose limit for radiation workers}

To derive the dose limit for radiation workers, ICRP assumed - on the basis of statistics and information given by the International labour organisation (ILO) - that a professional risk of $10^{-3}$ per year or a $3 \%$ lifetime risk due to the profession are the upper limits that are still acceptable for a working force. For a worker constantly exposed, an annual risk limit of $10^{-3}$ corresponds - using a simple and crude calculation - to an annual dose of $25 \mathrm{mSv}$, since ICRP uses a risk factor of $410^{-2} \mathrm{~Sv}^{-1}$. It is however not so trivial to compute the lifetime risk, because :

- it takes roughly 10 years (latency) after an exposition until an increase of solid tumours begins to appear ;

- the radiation dose is assumed to increase the annual spontaneous cancer risk by a fixed factor throughout the rest of the lifetime; this factor depends on age at exposure; the sum of all the annual increments results in the lifetime risk.

Figure 2 [2] shows the result of calculations based on the above assumptions. An additional assumption is that a workforce of 1000 persons (in this case females) starts to be exposed at the age of 18 and is constantly exposed up to the age of 65 with the same annual dose. The ordinate shows the death probability rate due to the exposure.

It can be seen that a constant dose of $15 \mathrm{mSv}$ per year would result in a maximum death probability of $10^{-3}$ per year at the age of 80 , which is the average life expectancy of females. (As females are statistically more sensitive to radiation than males, it is prudent to use female data for determining the dose limits.) Nevertheless, ICRP decided to recommend a dose limit of $20 \mathrm{mSv}$ per year [2] or, to be quite accurate, $100 \mathrm{mSv}$ in 5 years, which increases the death probability of females by $10^{-3}$ per year at an age of 70 (Fig. 2). This dose limit is judged by ICRP itself as being just short of unacceptable, and it is therefore recommended that optimisation procedures and dose constraints be used to decrease the actual annual doses much below $20 \mathrm{mSv}$.

The impression that $20 \mathrm{mSv}$ is too high as an average annual dose is shared by other organisations involved in radiation protection. Some of them even recommend dose limits that are more drastic than the ICRP dose limitation system. 


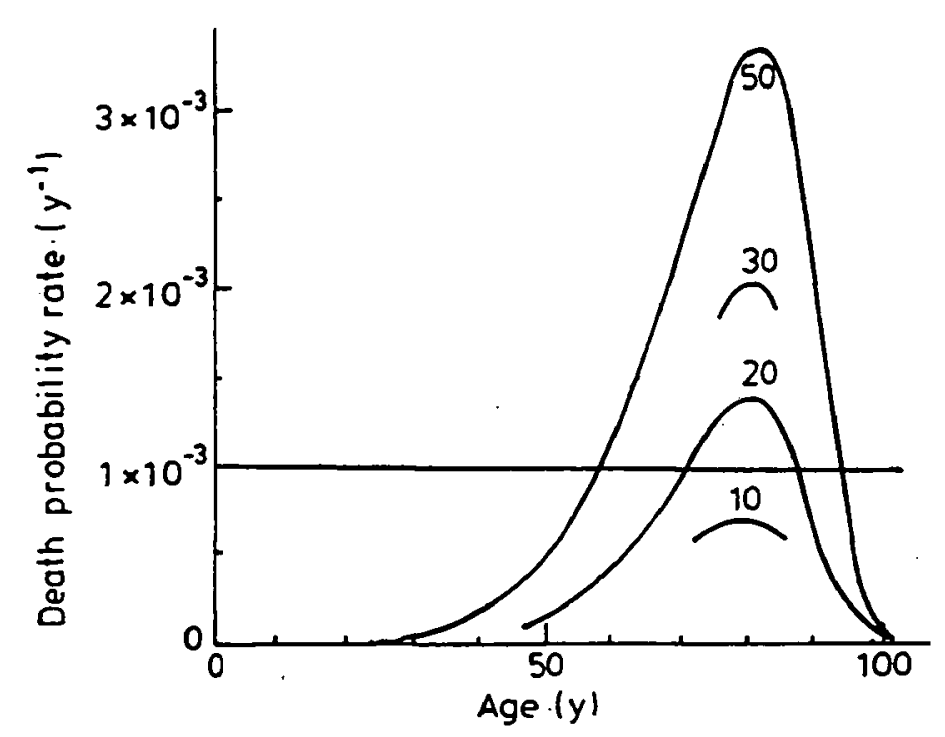

Fig. 2 - Death probability rate for exposure from age 18 to age 65 y. The curves are for females and for ICRP risk estimates using the multiplicative risk projection model. Various annual doses in mSv are shown, from [2, p. 39].

Probabilité annuelle de décès pour une exposition de 18 à 65 ans. Les courbes sont pour le sexe féminin à partir des estimations de risque de la CIPR en utilisant le modèle multiplicatif de projection du risque. Sont aussi figurées diverses doses annuelles (en mSv), d'après [2, p. 39].

The National council on radiation protection (NCRP) of the US recommends a lifetime dose limit that corresponds to the age in years of a radiation worker multiplied by $10 \mathrm{mSv}$ [6]. The lifetime dose should therefore never exceed $650 \mathrm{mSv}$. Germany has introduced a lifetime limit of $400 \mathrm{mSv}$ [1], in Sweden a lifetime limit of $700 \mathrm{mSv}$ has recently been adopted [9]. The National radiological protection board (NRPB) of the United Kingdom on the other hand recommends an annual dose constraint of $15 \mathrm{mSv}$ averaged over 5 consecutive years [7]. All these limits impose a maximum lifetime dose that is clearly below the $940 \mathrm{mSv}$ which could theoretically result from an annual exposure constantly at the ICRP - limit of $20 \mathrm{mSv}$ from age 18 to 65 .

In addition to the above, ICRP recommends a much sharper dose limit for pregnant women occupationally exposed to radiation : as soon as pregnancy is declared, the dose to the abdomen during the rest of pregnancy should not exceed $2 \mathrm{mSv}$ [2]. The aim of this recommendation is to achieve that the dose to the fetus stays below $1 \mathrm{mSv}$ (see Section 5).

\section{Influence of the dose and dose rate effectiveness factor (DDREF)}

The DDREF was, as already mentioned, introduced by ICRP to take into account that exposures during working conditions are less dangerous per unit dose than exposures delivered in a single shower e.g. by the atomic bomb. But how realistic is the choice of a DDREF of 2 ? A new report of UNSCEAR 
addresses this point [11]. The fact is that only very few human data are available giving some information concerning these questions. The main information stems from experiments with animals or cells in tissue cultures. The report concludes that the central value of all available data is about 4 . But it is concluded that for tumour induction, the DDREF adopted should, on cautious grounds, have a lower value, probably not more than 3. Assuming that a DDREF of 3 is more realistic than the introduced DDREF of 2 (which might be considered as too conservative) the theoretically derived dose limit of $15 \mathrm{mSv}$ (see Fig. 2) has to be corrected to $22 \mathrm{mSv}$. In other words, the tendency to further reduce the limit from $20 \mathrm{mSv} / \mathrm{a}$ to $15 \mathrm{mSv} / \mathrm{a}$ is counterbalanced by the tendency to raise the DDREF value from 2 to 3 . It seems, therefore, that the choice of a $20 \mathrm{mSv}$ annual dose limit with some flexibility, as done by ICRP, was a good decision and that this limit is going to last for quite a long time.

\section{The dose limit for the public}

It was an old praxis of ICRP to recommend that the dose limit of the most exposed members of the public should not exceed $10 \%$ of the limit for radiation workers. It is socially accepted to have a factor of 10 between the maximum risk to the general public and the maximum risk to workers. In its statement from the 1985 Paris meeting [3], the ICRP recommended that for members of the public the principal limit is $1 \mathrm{mSv}$ in a year, with allowance for some flexibility during a few exceptional years. In the new basic recommendations ICRP-60 [2] this limit of $1 \mathrm{mSv} / \mathrm{yr}$ was reconfirmed on the basis of the ambition that the death probability rate attributable to a prolonged exposure should not significantly exceed $10^{-4}$ per year at any time during lifetime. This risk limit is therefore a factor of 10 below the risk limit for workers (see section 3 ). This thinking, because of the increased sensitivity for radiation damage during childhood, leads to a ratio of 20 between the corresponding dose limits.

As it is now generally accepted that the fetus should be considered as a member of the public, it should therefore not be exposed above $1 \mathrm{mSv}$. That is the rationale behind the very restrictive dose limitation for pregnant woman mentioned in section 3 .

The limit of $1 \mathrm{mSv} / \mathrm{year}$ is a very low value and it should be remembered that natural doses are higher and that for a very large fraction of the population the medical dose also exceeds this limit. Although ICRP states clearly that nature and medicine are not submitted to this $1 \mathrm{mSv} / \mathrm{year}$ requirement, this situation is embarrassing. Perhaps one should rethink the appropriateness of the hypothesis introducing a factor 10 between the maximum risk for workers and the maximum risk for the public. In this very low dose region, where the linearity of the dose-effect relationship will never be proven and where certain hints suggest the presence of some sort of threshold, it might be better to apply a pragmatic approach. The ICRP dose limit for members of the public is inter- 
preted as an indicator of "normality". When the doses are below this limit, the situation is considered as being "normal". This unnecessary low limit of $1 \mathrm{mSv} / \mathrm{a}$ suggests that radon exposures and medical exposures are not normal and for certain regions contaminated by the Chernobyl fallout it prolonged by many years the so-called "return to normality".

\section{Hormesis and adaptive responses}

In recent years, experimental evidence has been accumulated showing that small doses of radiation may condition cells in such a way as to stimulate cellular repair processes. This stimulation of repair is known as "adaptive response". It has even been suggested that, as a result of adaptive response, low doses may be hormetic, that means beneficial to human health. Adaptation - as a short duration effect - is likely to coexist with detrimental late effects of low doses that may result in cancer induction. An important question, therefore, is to judge the balance between stimulated cellular repair and residual damage [10]. But the data from animal experiments and the limited human data available provide no evidence to conclude that the adaptive response in cells decreases the incidence of late effects such as cancer induction after low doses in a way that is not already accounted for by the DDREF.

\section{Conclusion}

The system of dose limitation introduced by ICRP in 1990 [2] is based on a prudent rationale and is coherent. This rationale itself relies on radiation risk considerations which are compared with other risks and their social acceptance. For the protection of workers it seems that ICRP made the best possible decision and that its recommended dose limits will probably last for quite a long time. For the protection of the public, however, the ICRP approach is less convincing.

\section{REFERENCES}

[1] GERMANY, Verordnung über den Schutz vor Schäden durch ionisierende Strahlung vom 13. Oktober 1976, 3. Kapitel, Paragraph 49 (1). (25.09.1990).

[2] INTERNATIONAL COMMISSION ON RADIOLOGICAL PROTECTION (ICRP) 1990 Recommendations (ICRP Publication 60). Ann. ICRP, 1991, 21 (1-3). Oxford: Pergamon press, 1991.

[3] INTERNATIONAL COMMISSION ON RADIOLOGICAL PROTECTION (ICRP) Statement from the 1985 Paris meeting of the International commission on radiological protection. Ann. ICRP, 1985, 15 (3) i-ii.

[4] KELLERER A.M., BARCLAY D. - Age dependences in the modelling of radiation carcinogenesis. Radiat. Prot. Dosim., 1992, 41, 273-281. 
IS THE RATIONALE BEHIND THE NEW DOSE LIMITS OF ICRP STILL VALID?

[5] LUCAS J.N., AWA A., STRAUME T., POGGENSEE M., KODAMA Y., NAKANO M., OHTAKI K., WEIER H.U., PINKEL D., GRAY J., LITTLEFIELD G. - Rapid translocation frequency analysis in humans decades after exposure to ionizing radiation. Int. J. Radiat. Biol., 1992, 62, 53-63.

[6] NATIONAL COUNCIL ON RADIATION PROTECTION AND MEASUREMENTS (NCRP) - Limitation of exposure to ionizing rädiation. (NCRP Report $\mathbf{n}^{\circ} 116$ ). Bethesda : NCRP, 1993.

[7] NATIONAL RADIOLOGICAL PROTECTION BOARD (NRPB) - Board advice following publication of the 1990 recommendations of ICRP. NRPB-M321, 1991.

[8] NATIONAL RESEARCH COUNCIL - Health effects of exposure to low levels of ionizing radiation (BEIR V). Washington : National academy press, 1990.

[9] SWEDISH RADIATION PROTECTION INSTITUTE - Sweden changes its dose limits. SSI News, $1994, n^{\circ} 4,1$.

[10] UNITED NATIONS SCIENTIFIC COMMITTEE ON THE EFFECTS OF ATOMIC RADIATION (UNSCEAR) - Sources and effects of ionizing radiation. New York : United Nations, 1994.

[11] UNITED NATIONS SCIENTIFIC COMMITTEE ON THE EFFECTS OF ATOMIC RADLATION (UNSCEAR) - Sources and effects of ionizing radiation. New York : United Nations, 1993.

[12] UNITED NATIONS SCIENTIFIC COMMITTEE ON THE EFFECTS OF ATOMIC RADIATION (UNSCEAR) - Sources, effects and risks of ionizing radiation. New York : United Nations, 1988. 